\title{
Vivência de mães de prematuros no processo de translactação
}

\section{Prematures mothers' experience in the process of translactation}

\author{
Natália Eirão Zulin; Mauren Teresa Grubisich Mendes Tacla²; Sarah Nancy \\ Deggau Hegeto de Souza ${ }^{3}$; Ariane Thaise Alves Monteiro ${ }^{4}$; Rosângela Aparecida \\ Pimenta Ferrari ${ }^{5}$
}

\begin{abstract}
Resumo
Objetivou-se compreender o significado que as mães de prematuros atribuíram à sua vivência com a utilização da técnica da translactação. Estudo de abordagem qualitativa, que entrevistou cinco mães de prematuros com menos de 32 semanas de gestação e/ou menos de 1.500 gramas, seis meses após alta hospitalar, no período de coleta de julho a setembro de 2011. Essas mães participaram do projeto integrado "Uma rede de apoio à família prematura". Critérios de inclusão: mães de recém-nascidos prematuros internados na unidade neonatal; utilização da translactação para o aleitamento materno de seu bebê durante hospitalização, alta hospitalar do bebê há no mínimo seis meses no momento da coleta de dados e participação no projeto. Quanto aos critérios de exclusão foram: não residir no município de Londrina e possuir menos de 18 anos. Duas categorias emergiram: Leite materno ao prematuro: essencial para o desenvolvimento e crescimento saudável e Translactação como recurso para sucesso na amamentação. O método de análise utilizado foi a temática proposto por Bardin. A translactação mostrou-se uma boa estratégia para promoção do aleitamento materno do prematuro. É necessário um serviço de saúde preparado com apoio multiprofissional e interdisciplinar para o manejo e incentivo do aleitamento materno durante a internação na unidade de cuidados neonatais.
\end{abstract}

Palavras-chave: Aleitamento materno. Prematuro. Métodos de alimentação. Recém-nascido de muito baixo peso.

\begin{abstract}
This study aimed to understand the meaning that mothers of premature attributed to their experience with the use of the technique of translactation. A qualitative study, which interviewed five mothers of premature infants less than 32 weeks gestation and / or less than 1,500 grams, six months after discharge from the hospital, in the period of collection from July to September 2011. These mothers participated in the integrated project "A support network to premature family". The inclusion criteria: mothers of premature infants admitted to the neonatal unit; that during the hospitalization of their baby, performed the technique of translactation, and their babies were discharged from the hospital for at least six months at the time of data collection and participation in the project. Exclusion criteria were being younger than 18 years and not residing in Londrina. Two categories emerged: Breast milk to premature: essential for healthy growth and
\end{abstract}

\footnotetext{
${ }^{1}$ Enfermeira. Residente de Enfermagem em Cuidados Intensivos no Adulto, Departamento de Enfermagem, Centro de Ciências da Saúde, Universidade Estadual de Londrina (UEL).

${ }^{2}$ Enfermeira. Doutora. Professora Adjunta do Departamento de Enfermagem, Área da Saúde da Criança e do Adolescente, Centro de Ciências da Saúde, Universidade Estadual de Londrina (UEL).

${ }^{3}$ Enfermeira. Doutora. Professora Adjunta do Departamento de Enfermagem, Área da Saúde da Criança e do Adolescente, Centro de Ciências da Saúde, Universidade Estadual de Londrina (UEL).

${ }^{4}$ Enfermeira. Mestranda em Enfermagem pela Universidade Estadual de Londrina. Pós-graduação - Modalidade Residência de Enfermagem em Saúde da Criança, Departamento de Enfermagem, Centro de Ciências da Saúde, Universidade Estadual de Londrina (UEL).

${ }^{5}$ Enfermeira. Doutora. Professora Adjunta do Departamento de Enfermagem, Área da Saúde da Criança e do Adolescente, Centro de Ciências da Saúde, Universidade Estadual de Londrina (UEL).
} 
development and Translactation as a resource for successful breastfeeding. The analysis method used was the theme proposed by Bardin. The translactation proved to be a good strategy to promote breastfeeding. A health service prepared with multidisciplinary and interdisciplinary support for the management and encouragement of breastfeeding during hospitalization in neonatal care unit is required.

Keywords: Breastfeeding. Premature. Feeding methods. Infant, very low birth weight.

\section{Introdução}

A prematuridade e suas complicações são as principais causas de mortalidade e morbidade neonatal (ex.: deficiências cognitivas e auditivas). O impacto em curto e longo prazo da prematuridade e suas implicações é traumatizante para os pais e acarretam alto custo para o sistema de saúde do Brasil (WHO, 2012).

O leite materno é o alimento ideal para o crescimento e o desenvolvimento do recémnascido $(\mathrm{RN})$, reduz os indicadores de morbidade e mortalidade infantil, promove a saúde física, mental e psíquica da criança e da mãe. Recomendase o aleitamento materno exclusivo até os primeiros seis meses e, após esse período, complementar adequadamente com a manutenção até os dois anos ou mais (BRASIL, 2009). Estudo aponta que o aleitamento materno exclusivo (AME) reduz significativamente o risco de desenvolver enterocolite necrotizante (SULLIVAN; et al, 2010), além de promover o crescimento e neurodesenvolvimento do bebê e incentivar o vínculo mãe-bebê (BRASIL, 2009).

Amamentar um prematuro hospitalizado é um grande desafio devido sua imaturidade fisiológica e neurológica, dificuldade em coordenar sucçãodeglutição-respiração e hospitalização prolongada, gerando na mãe sentimentos de incapacidade e estresse emocional que podem diminuir a lactação, além da ausência do contato precoce mãe-filho e início tardio do AME (SCOCHI et al, 2008).

A prematuridade é um fator que dificulta estabelecer o aleitamento materno e sua manutenção. A imaturidade do pré-termo pode resultar diversas consequências e comorbidades, necessitam assim de um aporte nutricional apropriado, sendo o leite materno, em especial o colostro de mãe de prematuro extremamente rico em aspectos nutricionais e imunológicos (CASTELLOTE, et al, 2011).

Nesta fase, as mães encaram o medo e a insegurança em relação à alimentação de seu filho prematuro (MELO, et al, 2013), exigindo dos profissionais de saúde um manejo adequado para promover a amamentação (SILVA; TAVARES; GOMES, 2014).

Quando se trata de prematuros internados em uso de sonda gástrica para alimentação, é preciso considerar como o leite materno pode ser oferecido para ajudar na transição da sonda ao seio materno. Se o RN apresentar prontidão oral para receber alimentação por via oral, a translactação é uma boa opção, pois é um método que consiste no estímulo precoce à sucção e o lactente poderá desfrutar de todas as vantagens que o leite materno lhe proporcionará (FUJINAGA, et al, 2013).

A translactação, além de auxiliar na transição da alimentação por sonda gástrica para o seio materno, também contribui para o aumento da produção de leite em mães com baixa produção láctea, estimulando a descida do leite. É uma adaptação da técnica da relactação, em que o leite ordenhado pela mãe é colocado em um recipiente ou seringa, uma ponta da sonda é conectada a essa seringa e a outra ponta é fixada próxima à aréola. $\mathrm{O}$ bebê, ao sugar o seio materno, recebe o leite tanto do recipiente como da mama. É uma prática que envolve mecanismos fisiológicos para realizar a transição da alimentação pela sonda ao seio materno (BRASIL, 2009).

Essa técnica envolve a participação ativa da mãe, que precisa ser orientada e estimulada na realização dessa prática, além da necessidade de ser acolhida em seus medos, insegurança e suas tensões 
cotidianas por ter um filho internado na Unidade de Terapia Intensiva Neonatal (UTIN).

Portanto, diante do exposto, o presente estudo teve como objetivo compreender o significado que as mães de prematuros atribuíram à sua vivência com a utilização da técnica da translactação na alimentação do seu filho.

\section{Método}

Trata-se de um estudo de abordagem qualitativa, realizado a partir de entrevistas com mães que tiveram seu bebê prematuro internado na unidade neonatal em um hospital no município de Londrina - PR.

Os sujeitos da pesquisa foram mães que durante a internação de seu bebê prematuro, realizaram a técnica da translactação. Essas mães participaram do projeto integrado "Uma rede de apoio à família prematura", desenvolvido na Unidade de Cuidados Intermediários Neonatais (UCIN) e na UTIN do hospital, com o objetivo de oferecer atenção e apoio às famílias dos bebês prematuros do nascimento à alta, disponibilizando auxílio frente aos cuidados com o recém-nascido (BENGOZI, et al., 2010).

Este projeto é um programa de apoio à família do prematuro implantado desde 2006, juntamente com o curso de Residência em Enfermagem Neonatal, tem como referencial teórico o Cuidado Centrado na Família. As atividades são desenvolvidas desde o nascimento, durante todo o processo de hospitalização e no seguimento realizado no domicílio e ambulatório, nas seguintes etapas: primeiro contato e apoio no dia do nascimento; primeira visita dos pais ao prematuro, preparo das mães e estímulo precoce ao aleitamento materno (AM), atendimento familiar individual semanal durante a hospitalização do prematuro; estímulo e preparo para o contato pele a pele, reuniões com grupo de pais; processo e treinamento da família nos cuidados do recém-nascido para a alta hospitalar; visita domiciliar antes e após a alta hospitalar; referência para a unidade de Saúde da Família e consultas de enfermagem no ambulatório (BENGOZI, et al., 2010). Essas famílias são atendidas pelas enfermeiras residentes e docentes do curso, com o apoio de uma equipe multidisciplinar constituída de docentes e residentes de medicina, equipe de enfermagem, assistente social, psicóloga e fonoaudióloga.

$\mathrm{Na}$ presente pesquisa, a participação na pesquisa levou em consideração os seguintes critérios de inclusão: mães de RN prematuros internados na unidade neonatal; utilização da translactação para o aleitamento materno de seu bebê, alta hospitalar do bebê há no mínimo seis meses no momento da coleta de dados e participação no projeto. Quanto aos critérios de exclusão: não residir no município de Londrina e ser menor de 18 anos. A população em estudo utilizou o método da translactação durante no ano de 2010. Durante esse período, utilizaram a técnica de translactação 29 mães, sendo que 11 residiam em outros municípios, oito eram menores de 18 anos, três não foram localizadas e duas se recusaram a participar da pesquisa. Sendo realizada entrevista com cinco mães, no período de julho a setembro de 2011.

Durante a internação do bebê, a família recebia orientações e incentivo para o aleitamento materno e a alimentação era oferecida pelo método da translactação com a ajuda de um membro da equipe de enfermagem ou apenas pela mãe, desde que se sentisse segura. A sucção em seio materno se iniciava quando o bebê alcançava estabilidade fisiológica, idade gestacional maior de 30 semanas e/ou prontidão oral com mais de 28 pontos, segundo instrumento proposto por Fujinaga, et al. (2013). Durante a internação, quando a mãe não estava presente, a dieta era oferecida somente por sonda nasogástrica.

Utilizou-se um roteiro semiestruturado, sendo a coleta de dados realizada por meio de entrevistas individuais na residência da mãe, com a seguinte pergunta norteadora: Conte-me como foi para você 
utilizar a técnica de translactação para amamentar seu filho.

Após assinatura do Termo de Consentimento Livre e Esclarecido (TCLE), deu-se início às entrevistas e para garantir o sigilo das participantes, estas foram identificadas por codinomes (M1, M2, M3, M4 e M5). O método de análise utilizado foi a temática proposto por Bardin (2011).

Este estudo foi aprovado pelo Comitê de Ética em Pesquisa Envolvendo Seres Humanos da Universidade Estadual de Londrina, sob o CAAE: 0039.0.268.000-11.

\section{Resultados e Discussão}

Participaram da pesquisa cinco mães com idade entre 18 e 39 anos. A maioria completou o ensino fundamental e não tinham ocupação formal. Três eram primíparas e duas multíparas. Todas tiveram bebês nascidos com menos de 32 semanas de gestação e/ou menos de 1.500 gramas. A experiência prévia com a amamentação foi relatada por apenas uma participante, tendo em vista a situação de primiparidade das demais e uma que não amamentou em outras gestações.

O tempo de aleitamento materno após a alta hospitalar foi satisfatório, ao considerar a dificuldade de estabelecer e manter a amamentação do bebê prematuro durante a hospitalização, sendo que quatro bebês foram amamentados por mais de seis meses e apenas um foi desmamado com menos de seis meses de idade. Este último foi o único que não obteve sucesso com a técnica da translactação.

O processo de análise de dados qualitativos permitiu a identificação de duas categorias: Leite materno ao prematuro: essencial para o desenvolvimento e crescimento saudável e Translactação como recurso para sucesso na amamentação.
Leite materno ao prematuro: essencial para o desenvolvimento e crescimento saudável

No decorrer de cada entrevista, o leite materno foi considerado o alimento essencial para o desenvolvimento e crescimento saudável do bebê, principalmente por ser prematuro.

As mães reconhecem o valor do leite materno por suas propriedades imunológicas, seu papel na maturação dos órgãos, proteção contra infecções e para o desenvolvimento saudável, além de promover a formação do vínculo mãe-filho.

[...] seria melhor para o desenvolvimento dele, ele cresceria bem melhor, o desenvolvimento seria melhor. Ficava forte, não pegava tanta gripe, protegia contra infecções. E mais, ia ser melhor para o desenvolvimento dele, ele ia crescer ótimo, ótimo, ótimo, ótimo (M1).

Eu acho muito importante para o bebê, ser alimentado com o leite da mãe[...], eu acho bom para a saúde do bebê, para todo recém nascido, ainda mais para prematuro. Vale muito mais o leite da mãe do que qualquer outro para ele bebe (M2).

$\mathrm{Eu}$ acho importante, por ele ser prematuro, principalmente para o desenvolvimento dele, desenvolvimento até dos órgãos internos que ainda não terminaram de se desenvolver [...] o meu leite foi essencial para o desenvolvimento dele, e cada dia a mais, é super importante (M3).

Em outro estudo, discursos das mães de prematuros evidenciam a importância biológica e nutricional do leite materno, assim como a aproximação e reconhecimento de mãe e filho, desenvolvendo um laço afetivo (BRAGA; ALMEIDA; LEOPOLDINO, 2012).

A gestação de risco e o nascimento de um filho prematuro podem ocorrer em um momento complicado na vida da mulher. Desde o pré-natal, durante a internação prolongada do prematuro e após a alta hospitalar, o apoio da família e da equipe de saúde têm papel fundamental e devem-se valorizar as influências socioculturais e psicológicas que podem interferir no decorrer do caminho, pois 
o desejo materno e apoio para a amamentação são essenciais para alcançar o sucesso na estimulação do aleitamento materno (DIOGO; SOUZA; ZOCCHE, 2011).

$\mathrm{O}$ projeto "Uma rede de apoio à família prematura" traz uma equipe de saúde que compartilha as informações com a família, fortalece e valoriza os sentimentos e dificuldades da mãe e família que estão sofrendo momentos de angustias e dúvidas (BENGOZI, et al., 2010).

A responsabilidade do sucesso ou falha no aleitamento materno não deve ser transferida apenas para a mãe, pois esta necessita de um serviço de rede de apoio com uma equipe de profissionais de saúde preparados para incentivála e auxiliá-la quanto à promoção do aleitamento materno exclusivo (DAVIN; ENDERS; SILVA, 2010).

O papel da equipe de enfermagem no aconselhamento e manejo da amamentação do bebê foi relatado e confirmado como importante e necessário, que oferece apoio e autoestima materna proporcionando, consequentemente, maior vínculo entre o binômio mãe/bebê, circunstância que influenciou positivamente na recuperação do recém-nascido.

Não, eu não tinha (experiência com a amamentação), foi lá no [...] que eles me ensinaram, porque eu não sabia [...]. Da outra quando era neném eu tentei, mas naquele tempo sabe, não tinha isso [...] agora tem apoio à amamentação, alimentação. Então eu fiquei perdida $[. .$.$] parecia que eu tava tendo a primeira filha$ e senti que eu estava aprendendo agora, aprendendo amamentação, sobre o leite como é importante, aprendi tudo agora (M4).

[...] dava uma força para a gente, falava para a gente ficar calma, que tinha que ter paciência, ajudava a cuidar (M1).

Ah! Eram muito atenciosas as meninas. [...] É um atendimento muito bom. Gostei muito delas. Ajuda a amamentar, sempre ajudou, porque a gente não sabe aí elas vão lá, ficam em cima, são muito importante (M2).
A comunicação efetiva entre o profissional, o usuário do serviço e a família constitui o primeiro passo para envolver todos ativamente na promoção do AME, principalmente em prematuros, devendo haver segurança e confiança mútua para obter sucesso neste processo (SANTANA; GOULART; CHLART, 2010).

Estudo revelou que um dos fatores que mais geraram insegurança e culpa nas mães foi a falta de conhecimento sobre o processo de amamentação. Tais sentimentos foram sanados quando houve o reconhecimento materno de que poderiam contar com o apoio da equipe de saúde da unidade (DAVIN; ENDERS; SILVA, 2010).

Os profissionais da saúde devem ser capazes de reconhecer esses sentimentos maternos para lhes oferecer informações pertinentes, em momentos oportunos para que não haja excesso de orientações, o que levam à desconfortos e confusões, podendo influenciar negativamente no aleitamento materno (DIOGO; SOUZA; ZOCCHE, 2011). É um momento de incluir a mãe nos cuidados do seu bebê, dar oportunidade relacionar-se com ele, estimular o vínculo e o contato pele-a-pele, atitude humanizada que diminui os sentimentos de exclusão resultante da permanência no hospital (BENGOZI, et al., 2010).

É necessário um serviço de saúde organizado com apoio multiprofissional e interdisciplinar para o manejo e incentivo do aleitamento materno, com ações educativas durante a internação na unidade de cuidados neonatais e no preparo para a alta hospitalar e acompanhamento pós-alta, que pode facilitar a adesão das mães ao aleitamento materno, ao incentivar e apoiar na superação de obstáculos frente à amamentação do bebê prematuro (SANTOS; DITTZ; COSTA, 2012).

No serviço de saúde, onde foi desenvolvida a pesquisa, as mães recebem apoio desde o dia do nascimento, quando o primeiro contato é conversado sobre sua história de amamentação e seu desejo, e discutido a importância do aleitamento 
materno para o filho prematuro. É incentivada a ordenhar precoce e sua continuidade durante toda internação, como citado com o projeto de apoio à família do prematuro. Existe também a parceria com o Banco de Leite Humano da instituição que auxilia na coleta, armazenamento e distribuição do leite materno para os bebês internados.

Esse conjunto de estratégias de apoio foi destacado nas falas das mães, demonstrando o comprometimento de equipe com essa prática.

Especificamente sobre a utilização da translactação com estratégia para o sucesso da amamentação do prematuro, levantou-se a categoria a seguir:

\section{Translactação como recurso para sucesso na amamentação}

Frente às dificuldades encontradas para 0 aleitamento materno dos prematuros e visando os imensos benefícios que o leite materno oferece, surgiu, nos discursos das mães, a influência da translactação para a estimulação do aleitamento materno.

A translactação foi relatada como uma experiência positiva para a maioria das mães. Fatores como aumento da produção láctea e maior contato mãe e filho também são apresentados nos discursos a seguir.

[...] eu não acreditava muito, que quanto mais leite a gente tira mais leite a gente tem [...] esse processo aí da sondinha que eu vi que era verdade, porque eu não tinha muito leite, mas com ela sugando com a sondinha no meu peito eu acho que eu comecei a produzir leite mais rápido. [...] na minha opinião eu acho que aprende mais rápido [...] ela ficava deitadinha no colo, ela já vai aprendendo pegar no bico do peito (M5).

Para mim foi uma experiência ótima [...] e a translactação ajuda, porque depois de tanto tempo, o leite começa a diminuir e as meninas falavam que por essa distância o leite até seca, mas com o contato e a vontade que a mãe tem de amamentar o leite volta (M3).
Atualmente, é crescente o número de estudos a respeito da translactação e os benefícios alcançados com a utilização desta técnica. Um deles demonstrou que a prática da translactação em prematuros aumenta a chance de manter o AME em cinco vezes mais quando comparado com o uso do copo (ROSSETTO, 2011). Neste estudo, também, notou-se que a prevalência do AME em prematuros que se adotou a técnica de translactação foi proporcionalmente o dobro dos prematuros em uso do copo na primeira quinzena após a alta hospitalar (ROSSETTO, 2011).

Nos discursos a seguir, apreendeu-se que o método facilitou a transição da sonda ao seio materno, bem como sentimento de prazer.

\begin{abstract}
Depois que ele saiu do CPAP a gente fez a translactação para ele não fazer tanto esforço e, aos poucos, foi diminuindo e assim ele largou da translactação, não precisando mais da seringa e ele começou a sugar só o peito e, a partir do momento que ele começou a sugar só o peito, a gente via que tinha aquele leite suficiente para ele, aí ele veio para casa e mamou até os 8 meses. Então eu achei que ajudou bastante (M3).
\end{abstract}

É interessante, ajuda muito, assim [...] pra mim foi mais fácil. Ajudou a ensinar beber, como eles iam pegar certinho o bico do peito [...] por causa dela (translactação) que a minha menina pegou até que rápido. Prá mim esse método de vocês foi mais rápido, foi fácil e muito bom (M5).

Sentimentos de medo, preocupação, insegurança foram expressos pelas mães quando os bebês não se beneficiaram com a translactação em curto prazo. A condição da prematuridade, fragilidade, imaturidade, a instabilidade hemodinâmica apontaram o fato de o bebê não estar preparado e não ter força para sugar. O longo e prolongado tempo de internação também provocou sofrimento, apreensão, inquietação e insegurança às mães e às famílias.

[...] alguns conseguiam, porque eles tinham força, já ela não, ela não tinha força para puxar, para sugar. [...] com a sondinha foi difícil. Ela não pegou mesmo, acho que porque ela era muito pequenininha (M4). 
[...] a gente fica muito preocupado né, porque o neném não consegue pegar, [...] porque não ia para casa, ia continuar no hospital e por causa disso, eu fiquei com medo (M2)

No comecinho eu achava que não ia dar muito certo não, eu achava, como eles são prematuros, eu achava a boquinha dela muito pequena e ela nem sabia pegar direito [...] qualquer coisinha e eu já pensava que não ia conseguir sustentar eles, que eles iam chorar de fome (M5).

A primeira mamada ele precisou do oxigênio [...] cada vez que ele se esforçava demais, ele poderia voltar para o oxigênio. Era difícil quando voltava para o oxigênio, ia prolongar a internação lá, daí eu iria me preocupar mais (M3).

A separação precoce imposta pela hospitalização e a longa internação tem como consequência a menor estimulação e a dificuldade em manter a lactação, agravando a insegurança e ansiedade materna, causando até a desistência da mãe em amamentar (SANTOS; DITTZ; COSTA, 2012). Dessa forma, o sucesso da translactação pode encorajar a mãe a manter a lactação de seu filho, sentindo-se mais competente nessa tarefa.

A importância do suporte adequado para mães de prematuros iniciarem precocemente o aleitamento materno e sua manutenção também foi mencionado em estudo com 32 mães de prematuros de muito baixo peso ao nascer, como o apoio da família e de outras mães. Fatores como a distância do hospital até suas casas, desgaste físico e mental, necessidade de gerenciar o tempo gasto com os afazeres domésticos, a falta de privacidade para ordenhar, retorno ao trabalho foram citados como barreiras para dar continuidade no AM (SISK; et al., 2010).

Uma das mães entrevistadas não obteve sucesso na translactação durante a hospitalização, embora tenha se dedicado muito para conseguir, pois acreditava que o bebê se adaptaria à técnica e logo iria sugar o seio materno.

Eu achei que ele ia até pegar sabe, eu empolguei e ia todo dia, levantava cedo e ia, o dia inteiro, [...] tentava fazer ele pegar, mas ele não pegava. Eu nem sei por que ele não pegou, porque é até que fácil. Um pouquinho que sugava o leite já vinha, mas ele não sugava, não sugava nada (M1).

Mesmo que haja forte desejo materno para amamentar uma criança prematura, nem sempre se torna realidade para algumas mães, ainda que se esgote todas as estratégias para viabilizá-la.

[...] me sentia mal, porque tinha mãe lá que podia amamentar e não queria dar o peito [...]. Tinha condições de amamentar, tinha leite e não queria amamentar, já eu tive até que tomar remédio para descer o leite, mas não tinha, secou, eu tomei remédio muito tempo para descer, mas não deu também, tentei a translactação e também não deu, ele não pegava (M1).

Neste caso, é importante que a equipe apoie a mãe no sentido de tranquilizá-la que o cuidado do filho vai muito além da amamentação e que há outras formas de cuidar.

Quanto ao uso da translactação, é preciso estar atento para a prontidão do RN para que se inicie a sucção, pois este é o momento, em que é preciso investir em ações que contemplem tanto a assistência da mãe como a do prematuro (SCOCHI, et al, 2010). Em estudo realizado em comparação o uso da translactação e uso do copo, concluiu-se que a prática da translactação foi mais efetiva para a transição da alimentação por gavagem, reforçando a avaliação da prontidão oral e apoio da equipe de multiprofissional de saúde (ROSSETTO, 2011).

Mesmo com o reconhecimento materno sobre a importância do aleitamento e seus inúmeros benefícios, a angústia causada pela prematuridade, à preocupação com o estado de saúde e a ansiedade até que o bebê possa iniciar a sucção dificultaram a transição ao seio materno.

Ai meu Deus do céu, eu ficava louca, aí nervosa. Eu ficava o dia inteiro lá, ia de manhã e ficava a tarde toda lá e ele não sugava, não mamava. [...] aí dava nervoso, chorava, ficava desesperada, imagina, o nenê já nasce prematuro e ainda não pega o peito, só era pela sonda, sonda, sonda, aí eu ficava nervosa, é complicado (M1). 
[...] a gente fica muito preocupada, porque o neném não consegue pegar, não pega de um jeito, não pega do outro, não pega no copo, não pega em nada e a gente fica apreensiva (M2).

A prematuridade, a hospitalização, o ambiente em que ele está inserido, a separação precoce mãefilho são fatores que geram medo e ansiedade nos pais. O nascimento de um filho prematuro modifica a imagem do bebê "perfeito" que era tão esperado, alterando também os planos da mãe, deixando o momento da amamentação em segundo plano, interferindo na manutenção da lactação durante a internação, assim como, após a alta hospitalar (SANTOS; DITTZ; COSTA, 2012).

Os profissionais da instituição do estudo realizam, durante toda internação, um conjunto de estratégias, entre eles, a translactação é baseada na avaliação da prontidão oral do bebê e no preparo técnico e emocional da mãe para essa prática. Reforça-se a necessidade de um acompanhamento integral e individualizado ao binômio mãe-bebê prematuro e família que precisam de apoio e orientação, além de ações em coletivo para relatos de experiências para favorecer a adesão à amamentação.

O projeto "Uma rede de apoio à família prematura" desenvolvido na instituição do estudo é um exemplo de acompanhamento integral e contínuo do prematuro, afirmando a necessidade de ampliar a assistência, oferecendo suporte à família, estabelecendo vínculo e confiança entre o profissional e família. Espera-se assim, melhorar a qualidade de vida desses prematuros e sua família, fortalecendo o aleitamento e materno e o cuidado ao bebê prematuro (BENGOZI, et al., 2010).

\section{Conclusão}

As mães reconheceram o valor do aleitamento materno para a recuperação do seu bebê, entretanto, diante do nascimento de uma criança prematura e as circunstâncias envolvidas geraram preocupações, angústias e ansiedades dificultando a manutenção do aleitamento materno.
A translactação mostrou-se uma boa estratégica no auxílio ao aleitamento materno, uma vez que as falas das mães indicaram aceitação e satisfação na realização da técnica, constituindo-se mais uma ferramenta capaz de incentivar, promover e manter a amamentação.

Desta forma, diante das dificuldades vivenciadas pelas mães de bebês prematuros, faz-se necessário um sistema de apoio profissional preparado para disponibilizar orientações e identificar as barreiras da amamentação para oferecer apoio, conforto, estimulação e manejo adequado, assim como, dispor de conhecimento das técnicas disponíveis a serem utilizadas.

Acredita-se que compreender este processo, na perspectiva da mãe que o vivencia, poderá subsidiar a atuação dos profissionais que trabalham com o aleitamento materno do prematuro, propiciando melhores resultados na utilização dessa estratégia em unidades neonatais.

\section{Referências}

BARDIN, L. Análise de conteúdo. São Paulo: Edições 70, 2011.279p.

BENGOZI, T. M.; SOUZA, S. N. D. H.; ROSSETTO, E. G.; RADIGONDA, B. ; HAYAKAWA, L. M.; RAMALHO, D. P. Uma rede de apoio à família do prematuro. Cienc Cuid Saude, v. 9, n. 1, p. 155-160, 2010.

BRAGA, P. P.; ALMEIDA, C. S.; LEOPOLDINO, I. V. Percepção materna do aleitamento no contexto da prematuridade. R. Enferm. Cent. O. Min, v. 2, n. 2, p. 151-158, 2012.

BRASIL. Ministério da Saúde. Secretaria de Atenção à Saúde. Departamento de Atenção Básica. Saúde da criança: nutrição infantil: aleitamento materno e alimentação complementar. Caderno de Atenção Básica, n.23 - Brasília: Ministério da Saúde, 2009.

CASTELLOTE, C.; CASILLAS, R.; RAMÍREZSANTANA, C.; PÉREZ-CANO, F. J.; CASTELL, M.; MORETONES, M. G., et al. Premature delivery influences the immunological composition of colostrums and transitional and mature human milk. $J$ Nutr, v. 141, p. 1181-7, 2011. 
DAVIN, R. M. B.; ENDERS, B. C.; SILVA, R. A. R. Sentimentos de mães ao amamentarem seus bebês prematuros em sistema de alojamento conjunto. Rev. Esc. Enf. USP, v. 44, n. 3, p. 713-18, 2010.

DIOGO, E. F.; SOUZA, T.; ZOCCHE, D. A. Causas do desmame precoce e suas interfaces com a condição socioeconômica e escolaridade. Enfermagem em Foco, v. 2, n. 1, p. 10-13, 2011.

FUJINAGA, C. I.; MORAES, S. A.; ZAMBERLANAMORIM, N. E.; CASTRAL, T. C.; ALMEIDA E SILVA, A.; SCOCHI, C. G. S. Validação clínica do instrumento de avaliação da prontidão do prematuro para início da alimentação oral. Rev. Latino-Am. Enfermagem, v. 21(Spec):[06 telas], 2013.

MELO, L. M.; MACHADO, M. M. T.; LEITE, A. J. M.; ROLIM, K. M. C. Prematuro: experiência materna durante amamentação em unidade de terapia intensiva neonatal e pós-alta. Rev Rene, v. 14, n. 3, p. 512-20, 2013.

ROSSETTO, E. G. O uso da translactação para $o$ aleitamento materno de bebês nascidos muito prematuros: ensaio clínico randomizado. 2011. $150 \mathrm{f}$. Tese (Doutorado em Enfermagem em Saúde Pública) Escola de Enfermagem de Ribeirão Preto-USP, Ribeirão Preto. 2011.

SANTANA, M. C. C. P.; GOULART, B. N. G.; CHLART, B. M.; MELO, A. M.; SILVA, E. H. a A., et al. Aleitamento materno em prematuros: atuação fonoaudiológica baseada nos pressupostos da educação para promoção da saúde. Ciênc. Saúde Coletiva, v. 15, n. 2, p. 411-17, 2010.

SANTOS, T. A. S.; DITTZ, E. S.; COSTA, P. R. Práticas favorecedoras do aleitamento materno ao recém-nascido prematuro internado na unidade de terapia intensiva neonatal. R. Enferm. Cent. O. Min, v. 2, n. 3, p. 438-450, 2012.

SCOCHI, C. G. S.; GAUY, J. S.; FUJINAGA, C. I.; FONSECA, L. M. M.; ZAMBERLAN, N. E. Transição alimentar por via oral em prematuros de um Hospital Amigo da Criança. Acta Paul. Enferm, v. 23, n.4, p. 54045, 2010 .

SILVA, L. M.; TAVARES, L. A. M.; GOMES, C. F. Dificuldades na amamentação de lactentes prematuros. Distúrb Comun, v. 26, n. 1, p. 50-59, 2014.
SISK, P.; QUANDT, S.; PARSON, N.; TUCKER, J. Breast Milk Expression and Maintenance in Mothers of Very Low Birth Weight Infants: Supports and Barriers. $J$ Hum Lact, v. 26, n. 4, p. 368-375, 2010.

WORLD HEALTH ORGANIZATION. Born too soon: the global action report on preterm birth. Geneva, Switzerland: World Health Organization, 2012. 
